The importance of system band broadening in modern size exclusion chromatography

AUTHORS: Alexandre GOYON ${ }^{1}$, Davy GUILLARME ${ }^{1}$, Szabolcs FEKETE ${ }^{1 *}$

${ }^{1}$ School of Pharmaceutical Sciences, University of Geneva, University of Lausanne, CMU Rue Michel Servet, 1, 1211 Geneva 4 - Switzerland

CORRESPONDENCE: Szabolcs FEKETE

Phone: +41223796334

Fax: +41223796808

E-mail: szabolcs.fekete@unige.ch 


\section{The importance of system band broadening in modern size exclusion chromatography}

\section{ABSTRACT}

In the last few years, highly efficient UHP-SEC columns packed with sub-3 $\mu \mathrm{m}$ particles were commercialized by several providers. Besides the particle size reduction, the dimensions of modern SEC stationary phases $(150 \times 4.6 \mathrm{~mm})$ was also modified compared to regular SEC columns $(300 \times 6$ or $300 \times 8 \mathrm{~mm})$. Because the analytes are excluded from the pores in SEC, the retention factors are very low, ranging from $-1<k<0$, resulting in very small column band variance. Therefore, the contribution of the system itself to peak variance can become significant under UHP-SEC conditions.

The goal of this study was to evaluate the loss of efficiency observed with three different instruments (regular HPLC, non-optimized UHPLC and fully optimized UHPLC) offering different system variances. It appears that the new $150 \times 4.6 \mathrm{~mm}$, sub-3 $\mu \mathrm{m}$ SEC columns cannot be employed on a regular HPLC instrument, since the efficiency loss was equal to 60 - $85 \%$, when analyzing mAb sample. Optimized UHPLC systems having very low extracolumn volumes (typically $V_{e c}<10 \mu \mathrm{L}$ ) have therefore to be used to properly operate these columns. Due to the instrument contribution to band broadening, the apparent efficiency of SEC columns packed with sub-2 $\mu \mathrm{m}$ particles can indeed be hampered when using inappropriate system. Considering the extra-column band broadening contribution of current UHPLC instruments, a further decrease of SEC column dimension is therefore not desired.

\section{Keywords:}

Size exclusion chromatography, kinetic efficiency, extra-column band broadening, aggregates, monoclonal antibodies, sub-2 $\mu \mathrm{m}$ SEC columns 


\section{INTRODUCTION}

Size exclusion chromatography (SEC) is a traditional technique, widely applied for protein characterization and quality control. Its main application is the quantitative determination of protein aggregates $[1,2,3]$.

In SEC, proteins are separated based on their difference in hydrodynamic volume in the mobile phase, by diffusion in and out of stagnant pores. Conventional SEC is typically performed using $6-8 \mathrm{~mm}$ ID $\times 300 \mathrm{~mm}$ columns packed with $5-10 \mu \mathrm{m}$ particles and operating at moderate pressure (typically $\Delta P<80$ bar) [4]. Ultra-high performance sizeexclusion chromatography (UHP-SEC) columns offer new opportunities to improve both the resolution and throughput. UHP-SEC columns packed with $1.7,1.8$ or $2.0 \mu \mathrm{m}$ particles with varying pore sizes of $125-900 \AA$ are now available in $150 \times 4.6 \mathrm{~mm}$ dimensions $[5,6,7,8,9]$. Very high pressures (up to 500 bar) can be generated when using such columns, leading to thermal effects and shear forces that might become critical for temperature- or pressuresensitive proteins, with an additional risk of on-column protein denaturation and aggregation $[10,11,12]$. In the meantime, UHP-SEC was found to be suitable for the routine characterization of monoclonal antibodies (mAbs) [13], confirming that pressure-, temperature- and salt-induced denaturation are strongly protein dependent $[14,15,16,17]$. The pressure itself can also impact the retention (elution) time, based on the Gibbs free energy. However, ideally in SEC - due to the different elution mechanism compared to sorptive chromatography - the elution volume of proteins (and therefore selectivity) should not be affected by pressure [18].

In UHP-SEC, the throughput was found to be in average three-times higher, compared to conventional SEC methods $[10,13]$ and the analysis time typically ranged between 3 and 8 minutes when using $150 \times 4.6 \mathrm{~mm}$ columns. An important aspect to consider when using very efficient $150 \times 4.6 \mathrm{~mm}$ SEC columns is the band dispersion due to the chromatographic system itself. As reported for reversed phase liquid chromatography (RPLC) separations, a suitable chromatographic system has to be employed to take the full benefits of small modern columns $[19,20,21,22]$. Indeed, in modern RPLC conditions, the column volume and 
related volumetric band variance are inherently low, due to the column dimensions $(50 \times 2.1$ $\mathrm{mm}$ i.d. columns), and hence significantly affected by the extra-column band variance. In SEC, narrow bore columns are not available, but it is also important to keep in mind that band variance $\left(\sigma_{c o l}^{2}\right)$ depends on the solute retention factor $\left(\sigma_{c o l}^{2} \sim(k+1)^{2}\right)$ too. Since the compounds are excluded from the internal pores in SEC, the retention factor is very low (between $-1<k<0$ ) and so does the $(k+1)^{2}$, resulting in a small column band variance. As shown in [23] for polymers, the extra-column band broadening of regular HPLC system was still acceptable with conventional $300 \times 6.8 \mathrm{~mm}$ SEC columns. Depending on the size of the solutes (that influences $(k+1)^{2}$, as large compounds have low values, since the largest compounds are more excluded and spend less time in the internal pores), extra-column band broadening represented between 2 and 13\% of the column's intrinsic band broadening [23]. Extra-column band broadening in SEC has also been investigated in other studies and it has been concluded that this contribution can be kept sufficiently low in most practical situations, when using conventional SEC columns $[3,23,24]$. It has also been shown that the most important source of extra-column band broadening for the SEC separation of polymers was the tube dispersion [24].

However, problems are expected when SEC columns are miniaturized, without concomitant adaptation of the instrumentation. In UHP-SEC practice, extra-column band broadening probably impacts the observed column efficiency of the $150 \times 4.6 \mathrm{~mm}$ SEC columns packed with sub-2 $\mu \mathrm{m}$ particles (due to the decreased volumetric band variance). The aim of this work was to evaluate the effect of extra-column dispersion on a (1) conventional HPLC, (2) a non-optimized UHPLC and (3) an optimized UHPLC systems, when operating $150 \times 4.6 \mathrm{~mm}$ $(1.8 \mu \mathrm{m})$ and $300 \times 4.6 \mathrm{~mm}(3 \mu \mathrm{m})$ SEC columns. The extra-column volumes and variances of the three systems were thoroughly measured and the column's intrinsic efficiency was determined for a commercial therapeutic mAb (partially excluded) and for uridine (nonexcluded, $t_{0}$ indicator). The apparent and remaining column efficiencies were evaluated. Finally, apparent plate heights $(H)$ for systems possessing various extra-column variances were calculated for different column volumes. 


\section{Experimental}

\subsection{Chemicals and columns}

Potassium chloride, potassium phosphate dibasic and hydrochloric acid were purchased from Sigma Aldrich (Buchs, Switzerland). Water was obtained from a Milli-Q Purification System from Millipore (Bedford, MA, USA). The aqueous mobile phase was used for one week.

Pertuzumab as therapeutic monoclonal antibody (mAb) was kindly provided by the Center of Immunology Pierre Fabre (Saint-Julien en Genevois, France), whereas blue dextran and uridine were purchased from Sigma Aldrich (Buchs, Switzerland).

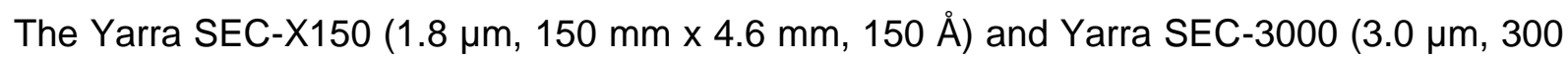

$\mathrm{mm} \times 4.6 \mathrm{~mm}, 290 \AA$ A) columns from Phenomenex (Torrance, CA, USA) were selected, as they showed high column efficiency in previous study [10].

\subsection{Equipment and software}

Three different liquid chromatography (LC) systems from Waters were selected to study the extra-column band broadening: 1) Waters Breeze HPLC, 2) Waters Acquity UPLC (first generation) and 3) Waters Acquity UPLC I-Class (last generation UHPLC). These instruments were equipped with a binary delivery pump, an autosampler and ultraviolet detector (UV) operating at $220 \mathrm{~nm}$. HPLC Breeze and Acquity UPLC used a loop offline injection device, while Acquity UPLC I-Class uses a flow through needle (FTN) injector. Acquity UPLC instrument was also supplied with a fluorescence detector (FL) in series before the UV detector. The non-optimised Acquity UPLC system represents an ideal compromise between the old HPLC Breeze system and the state-of-the-art Acquity UPLC IClass system. Measured extra-column volumes and details of the three systems are listed in Table 1.

Data acquisition and instrument control were performed by Empower Pro 3 software (Waters). Calculations and data transferring were achieved by using Excel (Microsoft). 


\subsection{Chromatographic conditions and standard preparation}

The mobile phase was composed of $200 \mathrm{mM}$ potassium phosphate dibasic buffer and 100 $\mathrm{mM}$ potassium chloride in water, $\mathrm{pH}=6.8$ (adjusted with hydrochloric acid). The flow rate was varied by $50 \mu \mathrm{L} / \mathrm{min}$ steps from $50 \mu \mathrm{L} / \mathrm{min}$ to the maximum operating flow rate of the column (400 $\mu \mathrm{L} / \mathrm{min})$. Measurements were performed at a temperature of $25^{\circ} \mathrm{C}$.

The pertuzumab (IgG1 mAb) sample was diluted from the concentrated commercial solution (30 $\mathrm{mg} / \mathrm{mL}$ ) to $2.0 \mathrm{mg} / \mathrm{mL}$ in water, whereas uridine and blue dextran solutions were prepared from powder at $2.0 \mathrm{mg} / \mathrm{mL}$ in water. The injection volume was $1 \mu \mathrm{L}$, corresponding to $2 \mu \mathrm{g}$ mass injected onto the column.

\section{Methodology and calculations}

When assuming that all contributions to peak variance are independent, and the peak has a Gaussian shape (distribution), the observed total variance $\left(\sigma_{\text {total }}^{2}\right)$ of a peak is the sum of two contributions:

$\sigma_{\text {total }}^{2}=\sigma_{c o l}^{2}+\sigma_{e c}^{2}$

Where $\sigma_{c o l}^{2}$ and $\sigma_{e c}^{2}$ account for the column variance and the system variance, respectively. The extra-column band broadening $\left(\sigma_{e c}^{2}\right)$ depends on the injected volume, the radius and length of connector tubing, the detector cell volume, the detector time constant, the flow rate, the diffusion coefficient of the sample and the mobile phase composition [20].

The purpose of this study was to determine the overall $\sigma_{e c}^{2}$ of our instruments. Typically, the overall extra-column variance is measured by leaving out the chromatographic column, directly connecting the inlet to the outlet tubing using a zero dead-volume (ZDV) union [25]. Obviously, this way $\sigma_{e c}^{2}$ is measured at lower pressure compared to the case when operating the column, and therefore the viscosity and diffusion coefficients can be different. However, with large molecules such as mAbs, the effect of pressure on extra-column band broadening can be assumed to be negligible [25]. Alternatively, $\sigma_{e c}^{2}$ can also be determined in the 
presence of a column $[26,27,28,29]$, but requires a series of compounds with similar physicochemical properties but different $\mathrm{k}$ values. This solution is hardly applicable to SEC.

The other difficulty is to accurately and precisely determine the peak variance. Again, several methods can be applied including (1) the peak width methods, (2) the moment methods, (3) the peak fitting methods and other (4) the convolution-deconvolution methods - but all suffers from either the lack of precision/accuracy or requires time consuming calculation processes [25]. Since the selected compounds eluted as asymmetrical peaks on all the three systems in absence of a column, the generic moment method was used to calculate the volumetric peak variance. Both the total and extra-column band broadening were derived from the first $\left(\mu_{1}\right)$ and the second $\left(\mu_{2}^{\prime}\right)$ central moments, which are calculated from the elution peak profiles:

$$
\mu_{1}=\frac{\sum_{i=1}^{n-1}\left(C_{i}+C_{i+1}\right)\left(t_{i}+t_{i+1}\right)}{2 \sum_{i=1}^{n-1}\left(C_{i}+C_{i+1}\right)}
$$

$$
\mu_{2}=\frac{\sum_{i=1}^{n-1}\left(C_{i}+C_{i+1}\right)\left(\left(\left(t_{i}+t_{i+1}\right) / 2\right)-\mu_{1}\right)^{2}}{\sum_{i=1}^{n-1}\left(C_{i}+C_{i+1}\right)}=\sigma_{e c}^{2}
$$

Where $\mathrm{Ce}(t)$ is the concentration of the sample compound in the mobile phase leaving from the system or column as a function of time $(t)$. The values of $\mu_{1}$ and $\mu_{2}^{\prime}$ are calculated by integrating the elution peak profile.

Both the extra-column and total band variances were measured at a series of flow rates varying by $50 \mu \mathrm{L} / \mathrm{min}$ steps from $50 \mu \mathrm{L} / \mathrm{min}$ to $400 \mu \mathrm{L} / \mathrm{min}$. Three compounds with different molecular weights were selected to cover the full elution range $(-1 \leq k \leq 0)$ range) of the SEC columns, and to study the impact of molecular diffusivity. A totally excluded molecule (blue dextran, $2000 \mathrm{kDa}$ ), a typical mAb which represents a routine analysis (pertuzumab, 148 $\mathrm{kDa}$ ), and a totally permeated small molecule (uridine, $0.2 \mathrm{kDa}$ ) were used in this study. 
The intrinsic column efficiency was calculated by subtracting the extra-column peak variance from the apparent peak variance obtained with the column on the Acquity I-Class system (which has the lowest extra-column contribution). The efficiency loss caused by the different systems was then evaluated. The remaining column efficiency $\left(E_{r}\right)$ was estimated as:

$$
E_{r}=100 \cdot \frac{\sigma_{c o l}^{2}}{\sigma_{c o l}^{2}+\sigma_{e c}^{2}}
$$

Observed and corrected plate height $(H)$ vs. linear velocity $(u)$ plots were constructed for observed and corrected pate heights. For this purpose, the plate numbers $(N)$ and then $H$ values were determined from the measured band variances:

$$
N=\frac{V_{0}^{2}}{\sigma^{2}}(1+k)^{2}
$$

Where $V_{0}$ is the column hold-up volume and $k$ is the solute retention factor. The total variance was considered for observed plate number, while the corrected variance was considered for the column's intrinsic plate number in eq. 5. Finally, $H$ was calculated as:

$$
H=\frac{L}{N}
$$

Where $L$ is the column length. To get the corrected $H$ values, the intrinsic $N$ was used in eq. 6.

The total permeation time $\left(t_{0}\right)$ and $k$ values were determined on the basis of uridine elution time.

The overall extra-column volumes $\left(V_{e x}\right)$ of the three LC systems were determined from the slope of linear fits of uridinie band apex time vs. reciprocal flow rate measured in absence of column.

\section{Results and Discussion}

\subsection{System dispersion}

First, the extra-column volume of the three LC systems was determined by injecting a small molecule (uridine) at various flow rates, by connecting the inlet and outlet tubes by a ZDV 
union. The observed peak apex times (based on the first central moment of the bands) were plotted as a function of reciprocal flow rate, and linear curves were fitted. This way, the slope of linear fits provide the extra-column volume, while the intercept corresponds to the time difference (delay) between the start of injection and beginning of data acquisition (offset time).

Figure 1 shows the observed plots and linear fits. As shown from the figure, the extra-column volume of the optimized UHPLC system (Acquity I-Class) was the lowest, $V_{e x}=7 \mu \mathrm{L}$. The non-optimized UHPLC instrument (Acquity UPLC) showed significantly larger system volume $\left(V_{e x}=24 \mu \mathrm{L}\right)$. This value is somewhat higher than reported for other Acquity systems $[19,30,31]$, but we have to keep in mind that there were two detectors set inline in this setup and also the original tubing has been changed to larger I.D. ones. This system is used for SEC and Hydrophobic Interaction Chromatographic (HIC) separations in our laboratory, and these modes require high salt concentration in the mobile phase. Therefore, to avoid continuous clogging and blocking of the thin tubes, the original inlet and outlet tubing were replaced by wider ones (see Table 1). Obviously, these modifications lead to higher extracolumn volume. Since the typical column diameter is between $4.6-8 \mathrm{~mm}$ in conventional SEC and HIC modes, no important loss of efficiency was observed up to now. The conventional HPLC system showed the largest extra-column volume equal to $V_{e x}=65 \mu \mathrm{L}$. This value is logically high, since this system is equipped with a standard $10 \mu \mathrm{L}$ flow cell and with quite long inlet and outlet tubing (600 and $700 \mathrm{~mm}$, respectively). Based on Figure 1, the offset times were very similar (and negligible) in all the three systems ( $0.01 \mathrm{~min})$.

Figure 2 shows some representative system band profiles observed with the three test analytes on the three systems in absence of the column and measured at a flow rate of 0.3 $\mathrm{mL} / \mathrm{min}$. For each analyte, the sharpest and most symmetrical bands were observed with the optimized UHPLC system. The non-optimized UHPLC system resulted in broader and more tailed bands, while the conventional system showed very broad and distorted bands. This ranking is in agreement with the systems' volume reported in Figure 1. However, an interesting finding is that the band variances (widths) of the different analytes were quite 
similar (or at least in the same order) on one given system, despite the huge differences in their diffusion coefficients. This suggests that the low axial and radial dispersion of large molecules compensates each other, and the final radial velocity profile in the tubing is similar to the one observed with small molecules possessing much higher diffusion coefficients. For aqueous mobile phase and ambient temperature, diffusion coefficients of $D_{M} \sim 1.5 \times 10^{-9} \mathrm{~m}^{2} / \mathrm{s}$ and $D_{M} \sim 1.1 \times 10^{-11} \mathrm{~m}^{2} / \mathrm{s}$ were considered for uridine and $\mathrm{mAb}$, respectively. However, on the other side, the Taylor-Aris dispersion in tubing should be inversely proportional to $D_{M}$. This should therefore result in less band broadening for larger molecules. Since we did not observe Gaussian profiles in our case, the residence time that molecules spend in the tubing is probably not sufficient for the radial diffusion, while the tubing is long enough for full axial dispersion. To conclude on the band profiles of different molecular weight analytes, it is hardly explainable since band dispersion in the tubing depends on numerous parameters including the capillary length, diameter, mobile phase velocity, axial dispersion, radial dispersion and band profile relaxation (which depends on mobile phase viscosity). Perhaps, the limiting case of no diffusion model (Atwood and Golay) can better describe the observations in this study [32,33] In addition, it was shown in many studies, that the calculated (expected) tube band variance is often significantly different from the experimentally observed ones [34,35]. The injector system and detector cells produce additional volume- and geometry dependent band variance. To avoid inaccuracy in the explanations of the system band variances, we remained empirical and concluded that the molecular weight of the analyte only had minor effect on extra-column band broadening with our three systems. Only slightly larger extra-column band broadening was observed with the $\mathrm{mAb}$ and blue dextran compared to uridine in one given LC system.

In Figure 3, the volumetric system dispersions were calculated for all analytes and systems at various flow rates. When injecting uridine, extra-column variance of only $\sigma_{e c}^{2}=1.8-3.5$ $\mu \mathrm{L}^{2}$ was observed with the optimized UHPLC system, while the non-optimized UHPLC and conventional HPLC systems resulted in $\sigma_{e c}^{2}=20-80 \mu \mathrm{L}^{2}$ and $\sigma_{e c}^{2}=300-500 \mu \mathrm{L}^{2}$, respectively (Figure $3 \mathrm{~A}$ ). For the mAb sample, a variance of $\sigma_{e c}^{2}=6-7 \mu \mathrm{L}^{2}$ was observed 
with the I-Class system, while the non-optimized UHPLC and conventional HPLC systems showed variances of $\sigma_{e c}^{2}=110-165 \mu \mathrm{L}^{2}$ and $\sigma_{e c}^{2}=350-1200 \mu \mathrm{L}^{2}$ (Figure $3 \mathrm{~B}$ ). Finally, for the largest test analyte (blue dextran), $\sigma_{e c}^{2}=5-7.5 \mu \mathrm{L}^{2}, \sigma_{e c}^{2}=120-180 \mu \mathrm{L}^{2}$ and $\sigma_{e c}^{2}=520-$ $1370 \mu \mathrm{L}^{2}$ were measured with the I-Class, the non-optimized UHPLC and the HPLC systems, respectively (Figure $3 \mathrm{C}$ ).

\subsection{Total peak dispersion and observed plate heights}

The band variances of the three compounds were measured with a $150 \times 4.6 \mathrm{~mm}(1.8 \mu \mathrm{m}$, $150 \AA$ ) and a $300 \times 4.6 \mathrm{~mm}(3 \mu \mathrm{m}, 290 \AA$ ) SEC columns. The $1.8 \mu \mathrm{m}$ material showed very high efficiency for mAbs, as reported in [36], this is why it was interesting to see if the total peak variance was affected by the extra-column band broadening.

Figure 4 shows the observed $H-u$ data and the corrected $H$ - $u$ fit when using the $1.8 \mu \mathrm{m} 150 \mathrm{x}$ 4.6 mm SEC column for uridine (A) and the mAb (B). Please note that blue dextran data was not shown, because this compound was eluted with a serious tailing on both columns, suggesting the presence of strong non-specific interactions with the stationary phase. Then, this compound cannot be used for the calculation of intrinsic column efficiency.

For uridine $(k=0$ and zone retention factor of $k "=1.44)$, the lowest observed plate height was $H_{\min }=3.9 \mu \mathrm{m}$ on the I-Class, $H_{\min }=5.1 \mu \mathrm{m}$ on the non-optimized UHPLC and $H_{\min }=$ $14.0 \mu \mathrm{m}$ on the conventional HPLC instrument. These results clearly show that if nonoptimized systems are used in SEC, the column efficiency can be strongly affected by the extra-column band broadening, despite of the large column volume. To better highlight the impact of systems on the observed plate heights, a curve was fitted on the corrected plate height values representing the intrinsic column efficiency. A common van Deemter type function resulted in good fit:

$H=A+\frac{B}{u}+C u$

Where $A, B$ and $C$ were considered only as model parameters in SEC, without giving them real physical meaning. When using the HPLC system, only $25-60 \%$ of the intrinsic column 
efficiency was maintained. On the non-optimized UHPLC system, $75-90 \%$ of the column efficiency was maintained, while the optimized UHPLC system allows to operate this SEC column very closely to its real performance $(96-99 \%)$.

The results were quite different when injecting a partially excluded mAb $(k=-0.42$ and zone retention factor of $k^{\prime \prime}=0.43$ ). Based on the retention factor, a very low peak variance is expected, but we have to keep in mind that large biomolecules often show different behavior compared to common small test analytes. Their diffusion speed inside the particles is indeed much lower than that of the totally penetrated uridine, not only due to their diffusion coefficients, but also to the obstructions that can take place with higher probabilities in narrow pores. Therefore, larger molecules penetrate more slowly through the internal pores than small molecules. Finally, broader peaks are always observed for more excluded large analytes compared to more penetrated small molecules. Figure $4 \mathrm{~B}$ shows the observed $\mathrm{H}-u$ data for pertuzumab. Again, by using the conventional HPLC system, the true efficiency of the column cannot be exploited. Only $13-43 \%$ of the column performance can be attained. The situation becomes better with a non-optimized UHPLC system as $45-65 \%$ of column efficiency can be kept. When operating this column on the optimized UHPLC system, practically the full performance was maintained (97 - $99 \%)$. To illustrate the intrinsic column efficiency, the following fit was applied for the corrected plate heights:

$H=A u^{1 / 3}+C u$

As expected for a mAb, no longitudinal diffusion ( $B$-term contribution) was observed under the applied conditions.

The plate heights observed with the less efficient and larger $300 \times 4.6 \mathrm{~mm}(3 \mu \mathrm{m}, 290 \AA)$ SEC column are shown in Figure 5. For uridine $\left(k^{\prime \prime}=1.20\right)$, the lowest observed plate heights were $H_{\min }=6.2,7.4$ and 12.7 on the optimized UHPLC, the non-optimized UHPLC and the HPLC systems, respectively (Figure $5 \mathrm{~A}$ ). Compared to the corrected plate heights, the full benefit of this column can be attained ( $100 \%$ column efficiency) with the optimized UHPLC system. However, despite of the large column volume $\left(V_{0}=4533 \mu \mathrm{L}\right.$ as measured), only $78-$ 
$95 \%$ of the efficiency remains, when operating the column on a not fully optimized UHPLC system and only $28-64 \%$ of the efficiency was observed on a conventional HPLC system. When analyzing mAb sample with the $300 \times 4.6 \mathrm{~mm} \mathrm{SEC} \mathrm{column} \mathrm{(Figure} 5 \mathrm{~B}$ ), the full column performance was maintained with the optimized UHPLC system and around $90 \%$ was still kept with the non-optimized UHPLC system. However, this large column loses 40 $70 \%$ of its performance when operating it on a conventional HPLC system.

To illustrate the loss of column efficiency, representative chromatograms of uridine and pertuzumab were shown on Figures 6 and 7 , at a flow rate of $0.3 \mathrm{~mL} / \mathrm{min}$ with the $150 \times 4.6$ $\mathrm{mm}, 1.8 \mu \mathrm{m}$ and the $300 \times 4.6 \mathrm{~mm}, 3 \mu \mathrm{m}$ Yarra SEC columns, respectively. An interesting point is that not only the peak width was affected by the system but also its elution time. At $0.3 \mathrm{~mL} / \mathrm{min}$, the HPLC system provides an additional residence time of around $0.22 \mathrm{~min}$, while it was only $0.08 \mathrm{~min}$ and $0.02 \mathrm{~min}$ in the UHPLC and the optimized UHPLC systems, respectively. This suggests that the accurate determination of column calibration curve and porosity requires the correction of elution times for the system residence time, especially on conventional HPLC systems. Otherwise, calibration data will not be reliable. When using the $150 \times 4.6 \mathrm{~mm}$ column, between 4 and $8 \%$ error can be made by not correcting the elution time of partially excluded analytes for system residence time and the error is close to $10 \%$ for a totally excluded analyte.

\subsection{Efficiency loss with UHP-SEC columns}

The remaining column efficiency has been calculated for both the $150 \times 4.6 \mathrm{~mm}$ and the 300 $\mathrm{x} 4.6 \mathrm{~mm}$ columns, when operating them with the three systems. Figure $8 \mathrm{~A}$ shows the use of the $1.8 \mu \mathrm{m} 150 \times 4.6 \mathrm{~mm}$ column for the mAb monomer peak. As can be seen, only the optimized UHPLC system was appropriate to operate this column without significant efficiency loss. Working with a non-optimized UHPLC system results in only $40-70 \%$ of the column performance. A standard HPLC system was clearly inappropriate to operate this SEC column. Since the longitudinal diffusion was negligible with a mAb, working at low flow rate always results in poorer utilization of column efficiency. From this point of view, it is better to 
work at high flow rate with this SEC column to take the benefit of column efficiency. However, working at high flow rate results in significant column pressure that can initiate oncolumn protein aggregation [10]).

The $300 \times 4.6 \mathrm{~mm}(3 \mu \mathrm{m})$ column can be operated with both optimized and non-optimized UHPLC systems (Figure 8 B). The efficiency loss was lower than $10 \%$ when working in the practically relevant flow rate range $(0.2 \leq F \leq 0.4 \mathrm{~mL} / \mathrm{min})$. Unfortunately, the conventional HPLC system was not able to provide sufficient performance, even with this relatively large SEC column. It is interesting to note that on the conventional HPLC system, $30-60 \%$ efficiency of the $3 \mu \mathrm{m}$ column can be attained, while only $15-40 \%$ can be reached with the more efficient $1.8 \mu \mathrm{m}$ column.

One can assume the case where a less efficient column apparently performs better than a more efficient one on a system that has important band broadening contribution. As shown in Figure $4 \mathrm{~B}$ and $5 \mathrm{~B}$, lower plate heights were measured with the $3 \mu \mathrm{m}$ packing compared to the $1.8 \mu \mathrm{m}$ one with the conventional HPLC system. To illustrate this situation, the observed (not corrected) plate heights were calculated as a function of system variance for the mAb monomer, when operating columns at $0.3 \mathrm{~mL} / \mathrm{min}$ (Figure 9). For the calculation, the experimentally observed plate heights were considered. In addition to the available $1.8 \mu \mathrm{m}$ $150 \times 4.6 \mathrm{~mm}$ and $3 \mu \mathrm{m} 300 \times 4.6 \mathrm{~mm}$ columns, another $3 \mu \mathrm{m}$ material packed into $300 \times 6$ $\mathrm{mm}$ (with the same intrinsic efficiency as the other $3 \mu \mathrm{m}$ packing) and a $1.8 \mu \mathrm{m}$ material packed into $150 \times 3 \mathrm{~mm}$ (narrow bore column, assumed to perform the same intrinsic efficiency as the $4.6 \mathrm{~mm}$ ID $1.8 \mu \mathrm{m}$ material) columns were assumed. Please note that $3 \mathrm{~mm}$ I.D. SEC columns were not commercially available. On the plot, the grey area indicates the system variance range of our optimized UHPLC system, the green area represents the variance range of our non-optimized UHPLC instrument, while the red area shows the band broadening contribution of our conventional HPLC system. When working with a highly optimized UHPLC system (e.g. $\sigma_{e c}^{2}<4 \mu \mathrm{L}^{2}$ ), columns packed with $1.8 \mu \mathrm{m}$ particles outperform the columns packed with $3 \mu \mathrm{m}$ particles, whatever the column volume. However, the $1.8 \mu \mathrm{m} 3 \mathrm{~mm}$ I.D. column loses a significant part of its apparent efficiency, due to the 
system variance. If the extra-column variance is larger than $6 \mu \mathrm{L}^{2}$, then the columns packed with $3 \mu \mathrm{m}$ perform lower plate heights than the $1.8 \mu \mathrm{m}$ one. This very efficient $3 \mathrm{~mm}$ I.D. SEC column is clearly not useful, since its benefit cannot be utilized on most of the currently available instrumentations. The $4.6 \mathrm{~mm}$ i.d. $1.8 \mu \mathrm{m}$ material is clearly more suitable, however when having a system with $\sim 100 \mu \mathrm{L}^{2}$ extra-column variance, this column performs the same plate height as the $3 \mu \mathrm{m}$ ones. If $\sigma_{e c}^{2}>100 \mu \mathrm{L}^{2}$, then again, this $4.6 \mathrm{~mm}$ i.d. column packed with $1.8 \mu \mathrm{m}$ particles becomes useless since its potential cannot be attained. Finally, the 300 x 4.6 and $300 \times 6$ mm columns are much more suitable for both conventional HPLC and not fully optimized UHPLC systems, but important efficiency loss is still expected with conventional systems (15-50\%).

\section{Conclusions}

In conventional SEC, $6-8 \mathrm{~mm}$ I.D. columns are mostly used, having length typically equal to $300 \mathrm{~mm}$. On those columns (possessing $V_{0}$ between 7500 and $15000 \mu \mathrm{L}-$ assuming $90 \%$ porosity), the peak variance is large enough not to be affected by the system dispersion. For a compound eluting at $k=-0.5$, peak variance of $\sigma_{c o l}^{2}=3000-10000 \mu \mathrm{L}^{2}$ is expected. However, if this material is packed into a $150 \times 4.6 \mathrm{~mm}$ column, which is the case for modern UHP-SEC columns, then peak variance will decrease down to $\sigma_{c o l}^{2}=200-400 \mu \mathrm{L}^{2}$. This value ranges in the order of the extra-column peak variance of conventional HPLC systems and therefore, such $150 \times 4.6 \mathrm{~mm}$ SEC columns cannot be operated on conventional systems without significant efficiency loss.

Based on our results - for a totally permeable small analyte - only $25-60 \%$ of the intrinsic column efficiency can be attained on conventional HPLC systems. The situation is even worse with a partially excluded analyte. When analysing a mAb with this very efficient $150 \mathrm{x}$ $4.6 \mathrm{~mm}$ SEC column, only $15-40 \%$ of the column potential is used. Optimized UHPLC systems having very low extra-column volumes (typically $V_{e c}<10 \mu \mathrm{L}$ ) have to be used to properly operate these columns. 
Another interesting finding is that conventional HPLC systems also have a huge impact on the apparent elution time of proteins - and therefore on mass-calibration curve - when working with $150 \times 4.6 \mathrm{~mm}$ I.D. columns. Then calibration data will not be reliable, except if corrected for extra-column residence time.

To conclude, we can state that state-of-the-art UHP-SEC columns of $150 \times 4.6 \mathrm{~mm}$ can only be operated on fully optimized UHPLC systems. Significant loss of efficiency is expected not only with conventional HPLC systems but also with not-optimized UHPLC systems too. It may happen that the apparent efficiency of columns packed with sub-2 $\mu \mathrm{m}$ particles can be much lower than that of those packed with larger particles $(3-5 \mu \mathrm{m})$ when operating them on conventional HPLC systems. A further decrease of SEC column dimension is therefore not desired and this direction should not be taken by chromatographic providers. Based on model calculations, a $150 \times 3 \mathrm{~mm}$ i.d. SEC column packed with $1.8 \mu \mathrm{m}$ particles show lower apparent efficiency than a 4.6 or $6 \mathrm{~mm}$ i.d. column packed with $3 \mu \mathrm{m}$ particles on most UHPLC systems (if $\sigma_{e c}^{2}>6 \mu \mathrm{L}^{2}$ ).

\section{Acknowledgements}

The authors wish to thank Tivadar Farkas from Phenomenex, for providing the Yarra SECcolumns. Jean-Luc Veuthey from the University of Geneva is acknowledged for his support and discussions. Alain Beck from Pierre Fabre is also acknowledged for providing the monoclonal antibody sample.

Davy Guillarme wishes to thank the Swiss National Science Foundation for support through a fellowship to Szabolcs Fekete (31003A 159494). 


\section{References}

[1] S. Fekete, D. Guillarme, Ultra-high-performance liquid chromatography for the characterization of proteins, Trends Anal. Chem. 63 (2014) 76-84.

[2] P. Hong, S. Koza, E.S.P. Bouvier, Size-exclusion chromatography for the analysis of protein biotherapeutics and their aggregates, J. Liq. Chromatogr. Relat.Technol. 35 (2012) 2923-2950.

[3] S. Fekete, A. Beck, J.-L. Veuthey, D. Guillarme, Theory and practice of size exclusion chromatography for the analysis of protein aggregates, J. Pharm. Biomed.Anal. 101 (2014) $161-173$.

[4] P. Diederich, S.K. Hansen, S.A. Oelmeier, B. Stolzenberger, J. Hubbuch, A sub-two minutes method for monoclonal antibody-aggregate quantification using parallel interlaced size exclusion high performance liquid chromatography, J. Chromatogr. A 1218 (2011) 9010-9018.

[5] E. Gazal, Can size exclusion chromatography (SEC) be done on sub-3 um particles? Presented at the 17th annual meeting of the Israel Analytical Chemistry Society, Tel Aviv, Israel, 2014.

[6] S. Fekete, D. Guillarme, P. Sandra, K. Sandra Chromatographic, electrophoretic, and mass spectrometric methods for the analytical characterization of protein biopharmaceuticals, Anal. Chem. 88 (2016) 480 - 507.

[7] S. Fekete, J.L. Veuthey, D. Guillarme, Modern column technologies for the analytical characterization of biopharmaceuticals in various liquid chromatographic modes, LC-GC Eur., Advances in Biopharmaceutical Analysis special issue (2015) 8 - 15.

[8] A. Goyon, A. Beck, J.L. Veuthey, D. Guillarme, S. Fekete, Comprehensive study on the effects of sodium and potassium additives in size exclusion chromatographic separations of protein biopharmaceuticals, J. Pharm. Biomed. Anal., (2016) in press

[9] X. Chen, Y. Ge, Ultrahigh pressure fast size exclusion chromatography for top-down proteomics, Proteomics, 13 (2013) 2563-2566. 
[10] S. Fekete, K. Ganzler, D. Guillarme, Critical evaluation of fast size exclusion chromatographic separations of protein aggregates, applying sub-2 $\mu \mathrm{m}$ particles, J. Pharm. Biomed. Anal., 78-79 (2013) 141-149.

[11] J. Vajda, R. Romling, New approaches to hplc analysis of antibody aggregates and fragments, Chromatogr. Today 5 (2012) 44-47.

[12] Y. Liu, W. Radke, H. Pasch, Coil-stretch transition of high molar mass polymers in packed-column hydrodynamic chromatography, Macromolecules 38 (2005) 7476-7484

[13] R. Yang, Y. Tang, B. Zhang, X. Lu, A. Liu, Y.T. Zhang, High resolution separation of recombinant monoclonal antibodies by size-exclusion ultra-high performance liquid chromatography(SE-UHPLC), J. Pharm. Biomed. Anal., 109 (2015) 52-61.

[14] T.W. Randolph, M. Seefeldt, J.F. Carpenter, High hydrostatic pressure as a tool to study protein aggregation and amyloidosis, Biochim. Biophys. Acta 1595 (2002) 224-234.

[15] N. Rivalain, J. Roquain, G. Demazeau, Development of high hydrostatic pressure in biosciences: Pressure effect on biological structures and potential applications in biotechnologies, Biotech. Adv. 28 (2010) 659-672.

[16] V.L. Pellerin, C. Balny, High pressure as a tool to study some proteins properties: conformational modification, activity and oligomeric dissociation, Inn. Food Sci. Emerg. Tech. 3 (2002) 209-221.

[17] J.M.R. Moore, T.W. Patapoff, M.E.M. Cromwell, Kinetics and Thermodynamics of Dimer Formation and Dissociation for a Recombinant Humanized Monoclonal Antibody to Vascular Endothelial Growth Factor, Biochemistry, 38 (1999) 13960-13967.

[18] J. De Vos, E.R. Kaal, R. Swart, M. Baca, Y.V. Heyden, S. Eeltink, Aqueous sizeexclusion chromatographic separations of intact proteins under native conditions: Effect of pressure on selectivity and efficiency, J. Sep. Sci. 39 (2016) 689-695.

[19] S. Fekete, I. Kohler, S. Rudaz, D. Guillarme, Importance of instrumentation for fast liquid chromatography in pharmaceutical analysis, J. Pharm. Biomed. Anal. 87 (2014) 105-119. 
[20] S. Fekete, J. Fekete, The impact of extra-column band broadening on the chromatographic efficiency of $5 \mathrm{~cm}$ long narrow-bore very efficient columns, J. Chromatogr. A 1218 (2011) 5286-5291.

[21] F. Gritti, C.A. Sanchez, T. Farkas, G. Guiochon, Achieving the full performance of highly efficient columns by optimizing conventional benchmark high-performance liquid chromatography instruments, J. Chromatogr. A 1217 (2010) 3000-3012.

[22] N. Wu, A.C. Bradley, C.J. Welch, L. Zhang, Effect of extra-column volume on practical chromatographic parameters of sub-2-mum particle-packed columns in ultra-high pressure liquid chromatography, J. Sep. Sci. 35 (2012) 2018-2025.

[23] S.T. Popovici, Towards small and fast size-exclusion chromatography (PhD thesis), Van't Hoff Institute for Molecular Sciences (HIMS), University of Amsterdam, Netherlands, 2004.

[24] G. Grznárová, M. Polakovica, P. Acai, T. Görner, Extra-column dispersion of macromolecular solutes in aqueous-phase size-exclusion chromatography, J. Chromatogr. A 1040 (2004) 33-43.

[25] Y. Vanderheyden, K.Vanderlinden, K. Broeckhoven, G. Desmet, Problems involving the determination of the column-only bandbroadening in columns producing narrow and tailed peaks, J. Chromatogr. A, 1440 (2016) 74-84.

[26] H. Poppe, J. Paanakker, M. Bronckhorst, Peak width in solventprogrammedchromatography. I. General description of peak broadening insolventprogrammed elution, J. Chromatogr. 204 (1981) 77.

[27] W. ThKok, U.A. Th Brinkman, R.W. Frei, H.B. Hanekamp, Use of conventionalinstrumentation with microbore columns in high-performance liquidchromatography, J. Chromatogr. 237 (1982) 357.

[28] H.H. Lauer, G.P. Rozing, The selection of optimum conditions in HPLC I. Thedetermination of external band spreading in LC instruments,Chromatographia 14 (November (11)) (1981) 641-647. 
[29] F. Gritti, G. Guiochon, Effect of the pressure on pre-column sample dispersiontheory experiments, and practical consequences, J. Chromatogr. A 1352(2014) 20-28.

[30] S. Fekete, R. Berky, J. Fekete, J.L. Veuthey, D. Guillarme, Evaluation of a new wide pore core-shell material (Aeris ${ }^{\mathrm{TM}}$ widepore) and comparison with other existing stationary phases for the analysis of intact proteins, J. Chromatogr. A, 1236 (2012) 177-188.

[31] S. Fekete, D. Guillarme, Kinetic evaluation of new generation of column packed with 1.3 um core-shell particles, J. Chromatogr. A, 1308 (2013) 104-113.

[32] J.G. Atwood, M.J.E. Golay, Dispersion of peaks by short straight open tubes in liquid chromatography systems, J. Chromatogr. 218 (1981) 97-122.

[33] M.J.E. Golay, J.G. Atwood, Early phases of the dispersion of a sample injected in poiseuille flow, J. Chromatogr. 186 (1979) 353-370.

[34] S.L. Tooper, Extra-column band broadening in ultrahigh performance liquid chromatography, Thesis work, University of Pittsburg, 2011

[35] K.J. Fountain, U.D. Neue, E.S. Grumbach, D.M. Diehl, Effects of extra-column band spreading, liquid chromatography system operating pressure, and column temperature on the performance of sub-2-um porous particles, J. Chromatogr. A, 1216 (2009) 5979-5988.

[36] A. Goyon, A. Beck, O. Colas, K. Sandra, D. Guillarme, S. Fekete, Evaluation of size exclusion chromatography columns packed with sub- $3 \mu \mathrm{m}$ particles for the analysis of protein biopharmaceutical proteins, J. Chromatogr. A, submitted 
Tables

Table 1: Detailed configuration of a (1) conventional HPLC (Waters Breeze), (2) a nonoptimized UHPLC (first generation of Waters Acquity UPLC) and (3) optimized UHPLC (Waters Acquity UPLC I-Class) systems. 


\section{Figure captions}

Figure 1. Estimation of extra-column system volumes for a conventional HPLC (red), a nonoptimized UHPLC (green) and an optimized UHPLC system (black).

Figure 2. Comparative band profiles of uridine (A), pertuzumab $(B)$ and blue-dextran $(C)$ in absence of column at $0.3 \mathrm{~mL} / \mathrm{min}$ on different LC systems (ambient temperature, injected volume of $1 \mu \mathrm{L}$, aqueous mobile phase).

Figure 3. System dispersion on three LC systems observed with uridine $(A)$, pertuzumab monomer (B) and blue-dextran (C).

Figure 4. $\mathrm{H}$-u curves observed with $150 \times 4.6 \mathrm{~mm}, 1.8 \mu \mathrm{m}$ Yarra column for uridine (A) and pertuzumab (B) on three LC systems (ambient temperature, injected volume of $1 \mu \mathrm{L}$, aqueous mobile phase).

Figure 5. $\mathrm{H}-u$ curves observed with $300 \times 4.6 \mathrm{~mm}, 3 \mu \mathrm{m}$ Yarra column for uridine (A) and pertuzumab (B) on three LC systems (ambient temperature, injected volume of $1 \mu \mathrm{L}$, aqueous mobile phase).

Figure 6. Experimental peaks on $150 \times 4.6 \mathrm{~mm}, 1.8 \mu \mathrm{m}$ Yarra column, when injecting uridine (A) and pertuzumab (B) at $F=0.3 \mathrm{~mL} / \mathrm{min}$ (ambient temperature, injected volume of $1 \mu \mathrm{L}$, aqueous mobile phase).

Figure 7. Experimental peaks on $300 \times 4.6 \mathrm{~mm}, 3 \mu \mathrm{m}$ Yarra column, when injecting uridine (A) and pertuzumab (B) at $F=0.3 \mathrm{~mL} / \mathrm{min}$ (ambient temperature, injected volume of $1 \mu \mathrm{L}$, aqueous mobile phase). 
Figure 8. Remaining column efficiency vs. linear velocity on different systems, when injecting pertuzumab monomer on the $150 \times 4.6 \mathrm{~mm}, 1.8 \mu \mathrm{m}(\mathrm{A})$ and $300 \times 4.6 \mathrm{~mm} 3 \mu \mathrm{m}$ Yarra (B) columns.

Figure 9. Expected observed $H$ vs. extra-column system variance for various SEC column dimensions and for 1.8 and $3 \mu \mathrm{m}$ packings, when injecting $\mathrm{mAb}$ monomer $(F=0.3 \mathrm{~mL} / \mathrm{min}$, ambient temperature, injected volume of $1 \mu \mathrm{L}$, aqueous mobile phase). 
Table 1.

Instrument

inlet tubing

outlet tubing

flow cell volume

total extra-column

loop volume

i.d. $(\mathrm{mm}) \times$ length $(\mathrm{mm})$

i.d. $(\mathrm{mm}) \times$ length $(\mathrm{mm})$

volume $(\mu \mathrm{L})$

$(\mu \mathrm{L})$

Waters HPLC Breeze

$0.125 \times 600$

$0.125 \times 700$

$(\mu \mathrm{L})$

$0.125 \times 400$

$0.100 \times 250+0.125 \times 150$

$2+0.5$

$0.075 \times 300$

$0.065 \times 300$

0.5

65

24

100

Waters Acquity UPLC I-Class

7

NA 


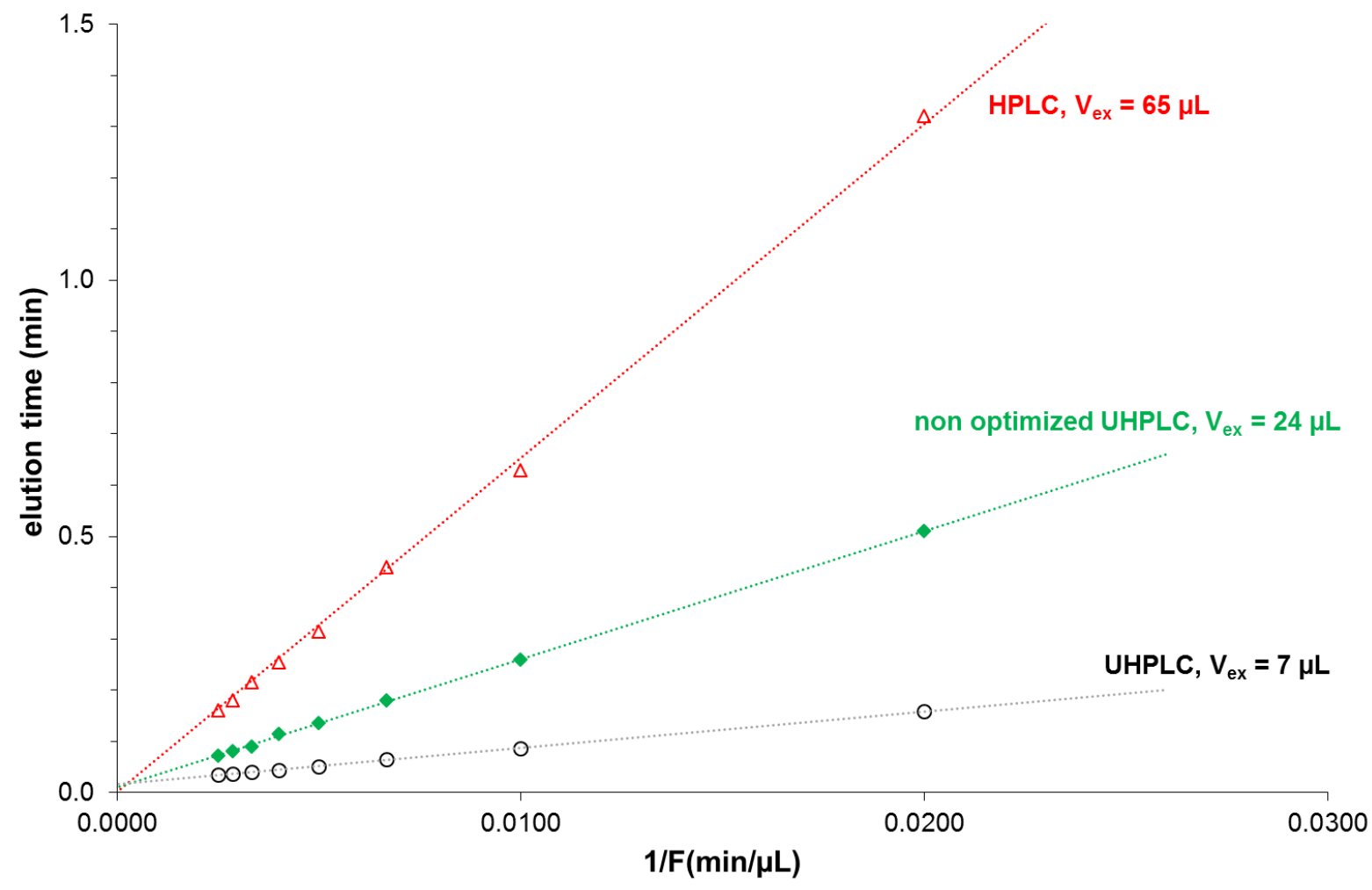

Figure 1. 

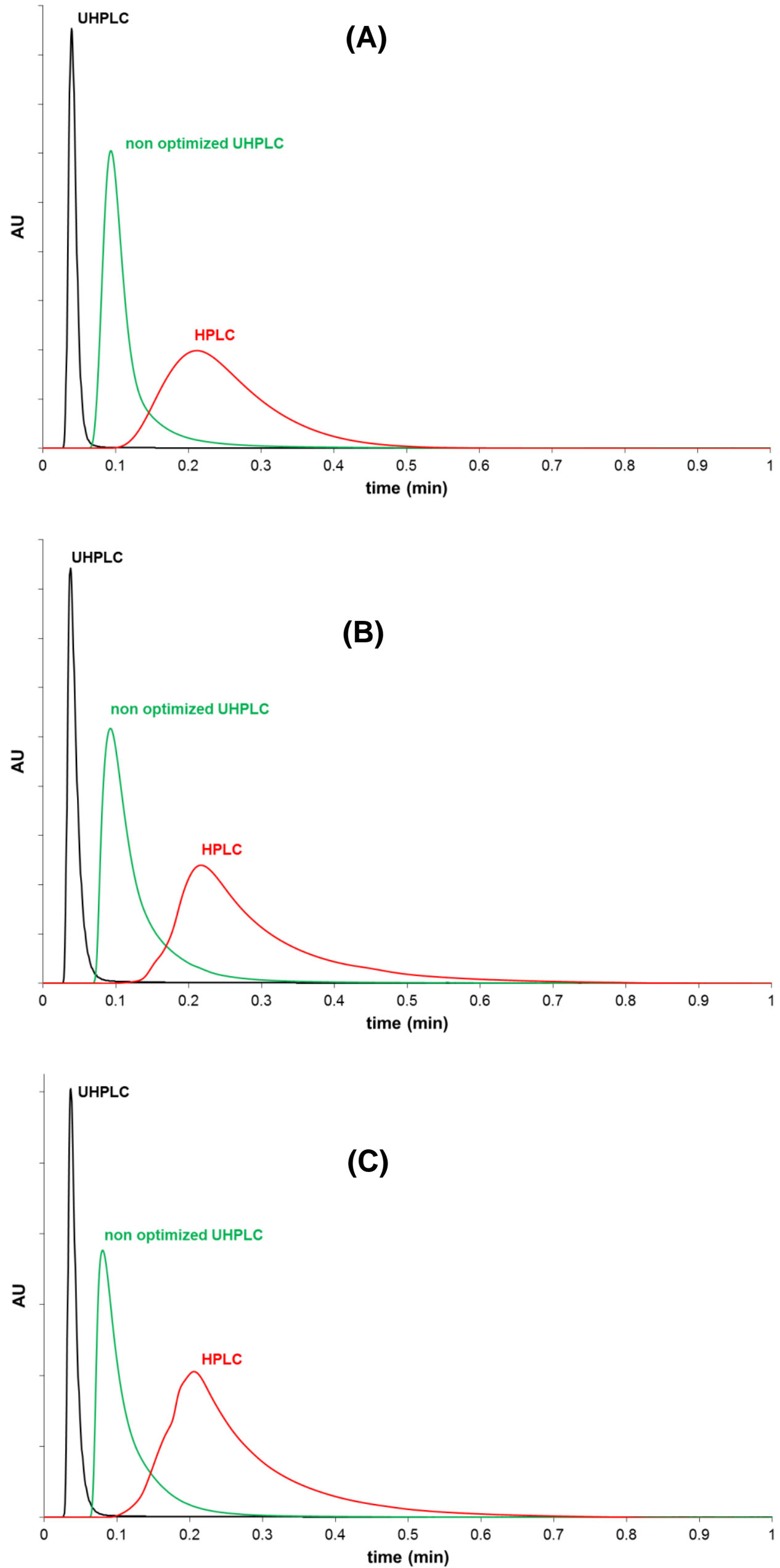

Figure 2. 

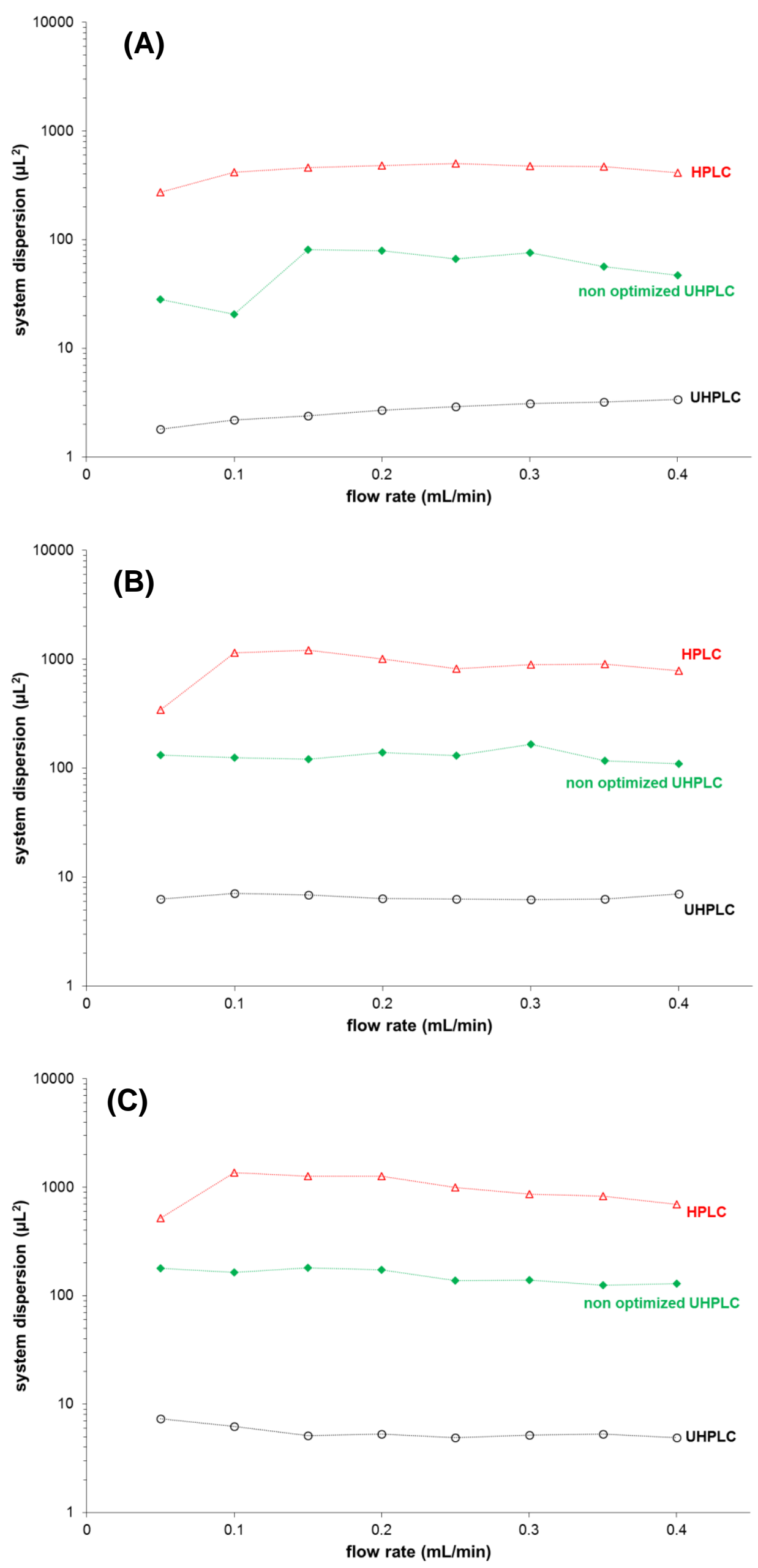

Figure 3. 

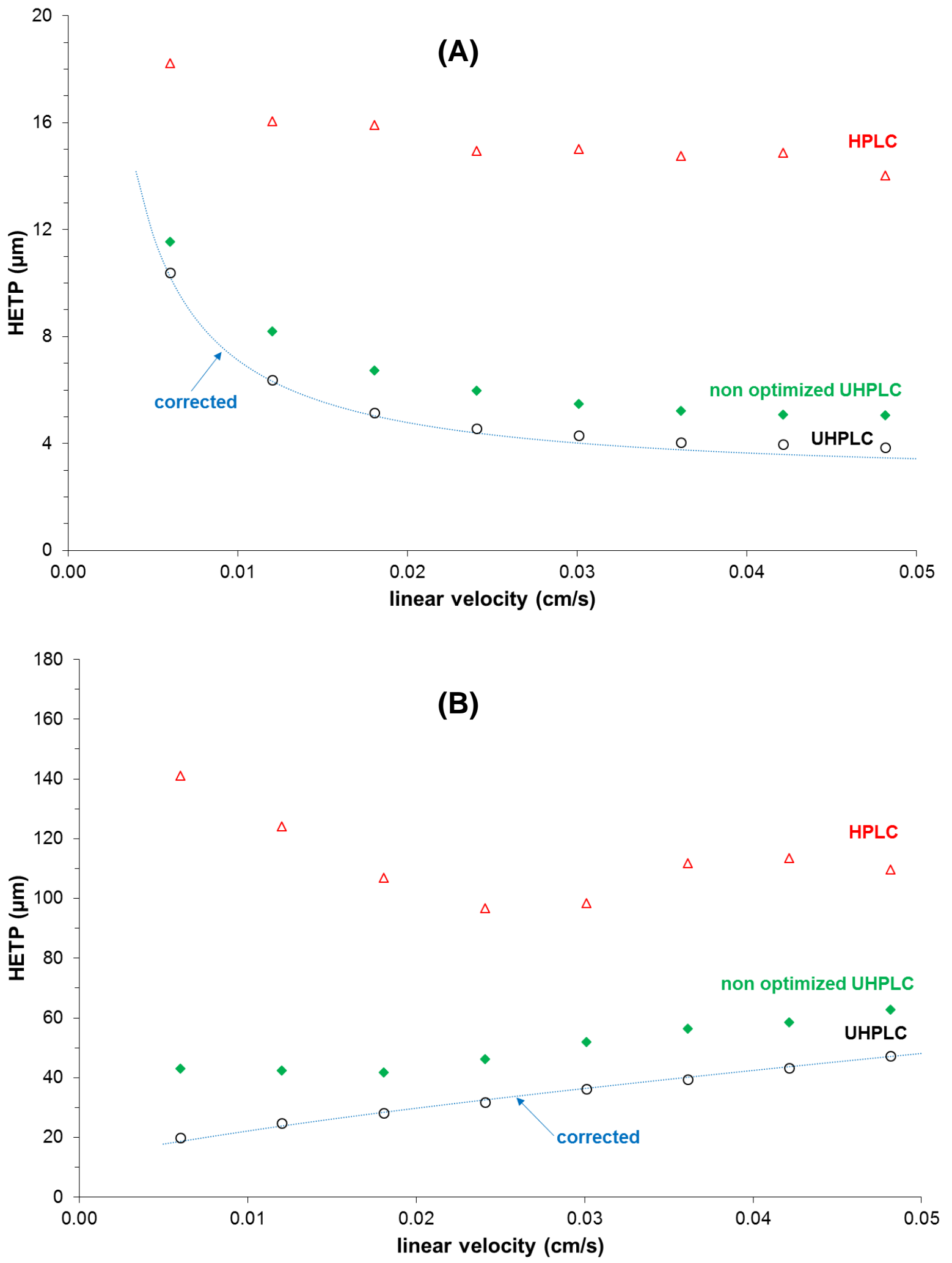

Figure 4 . 

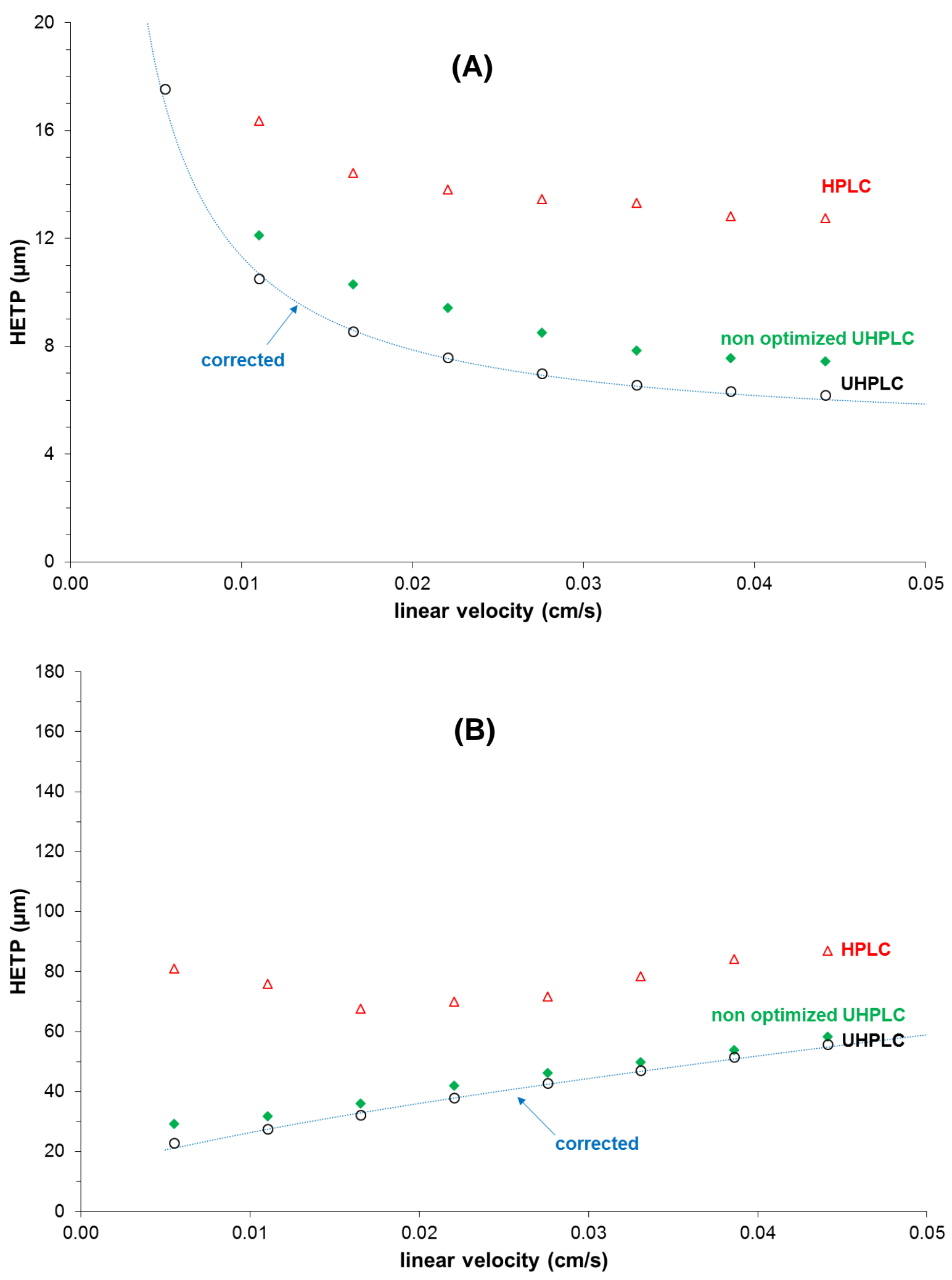

Figure 5. 

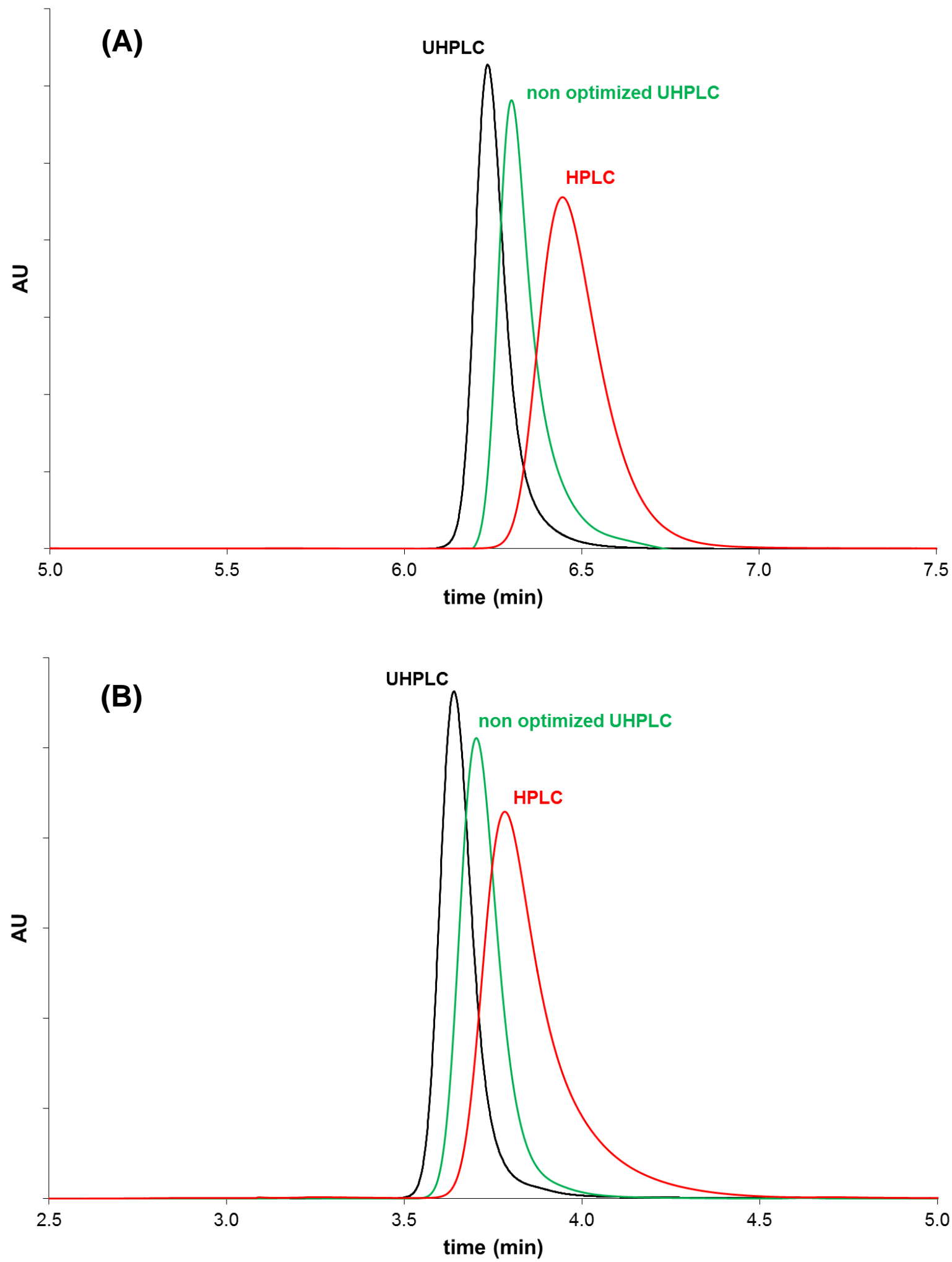

Figure 6. 

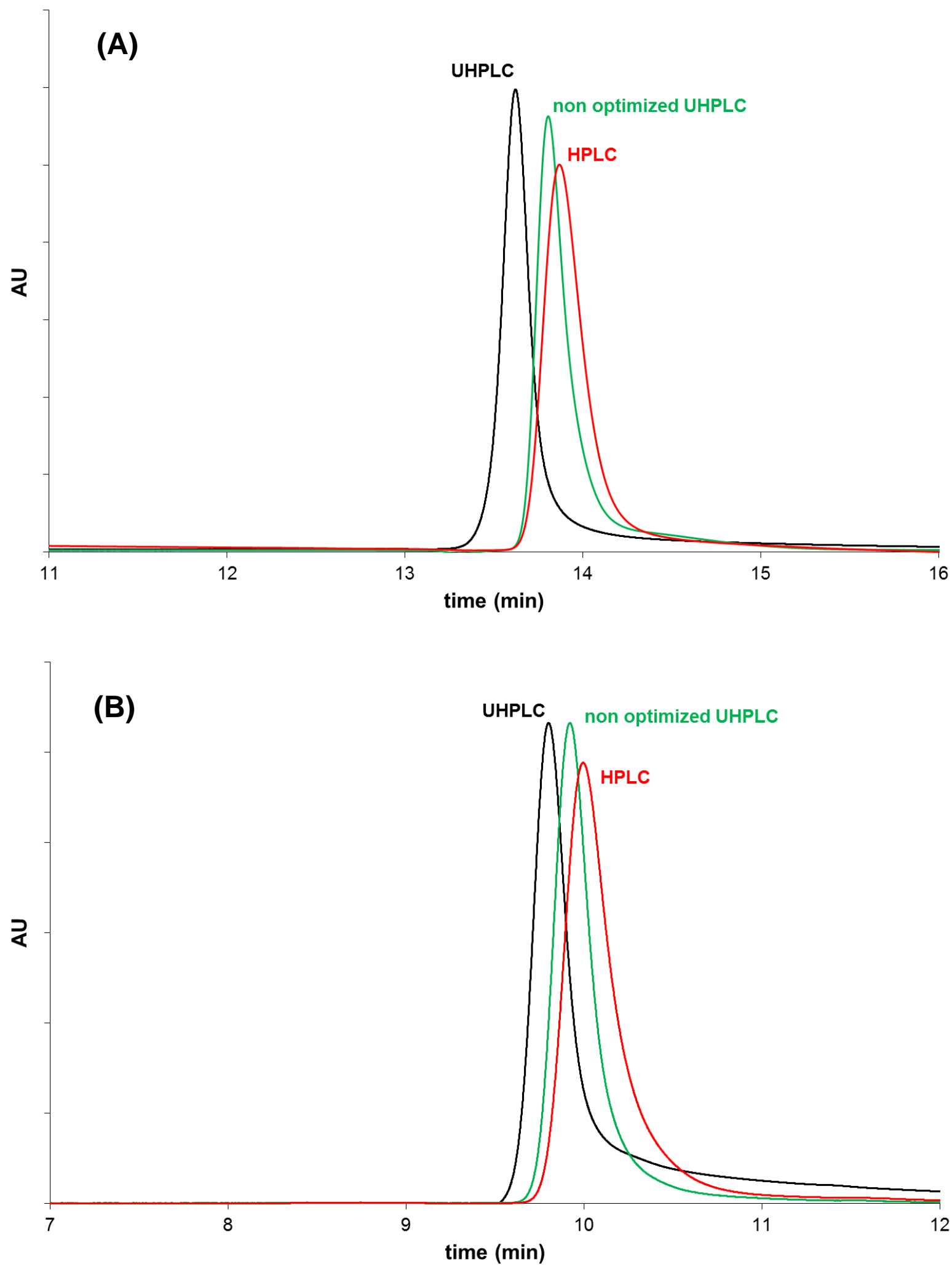

Figure 7. 

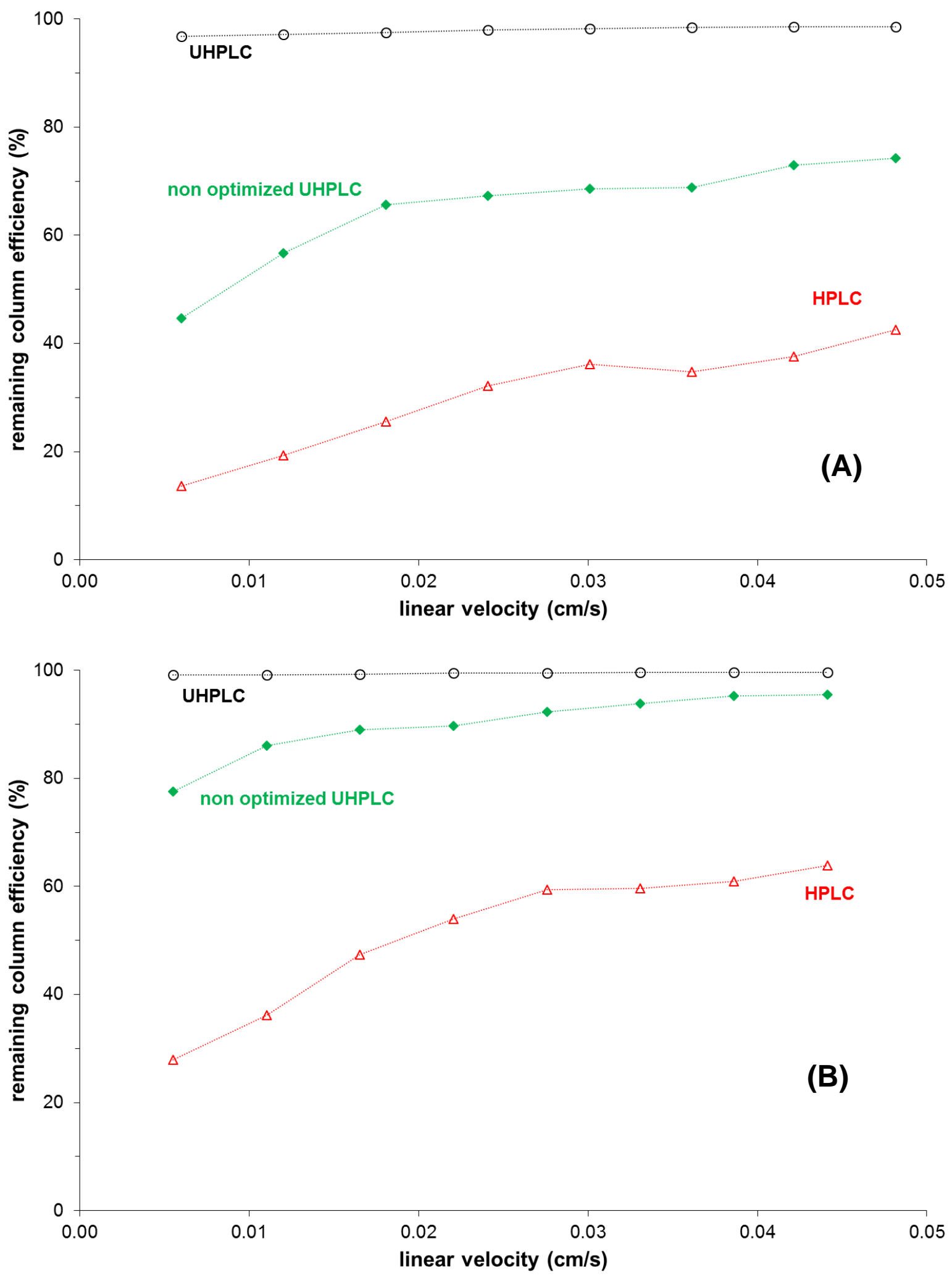

Figure 8. 


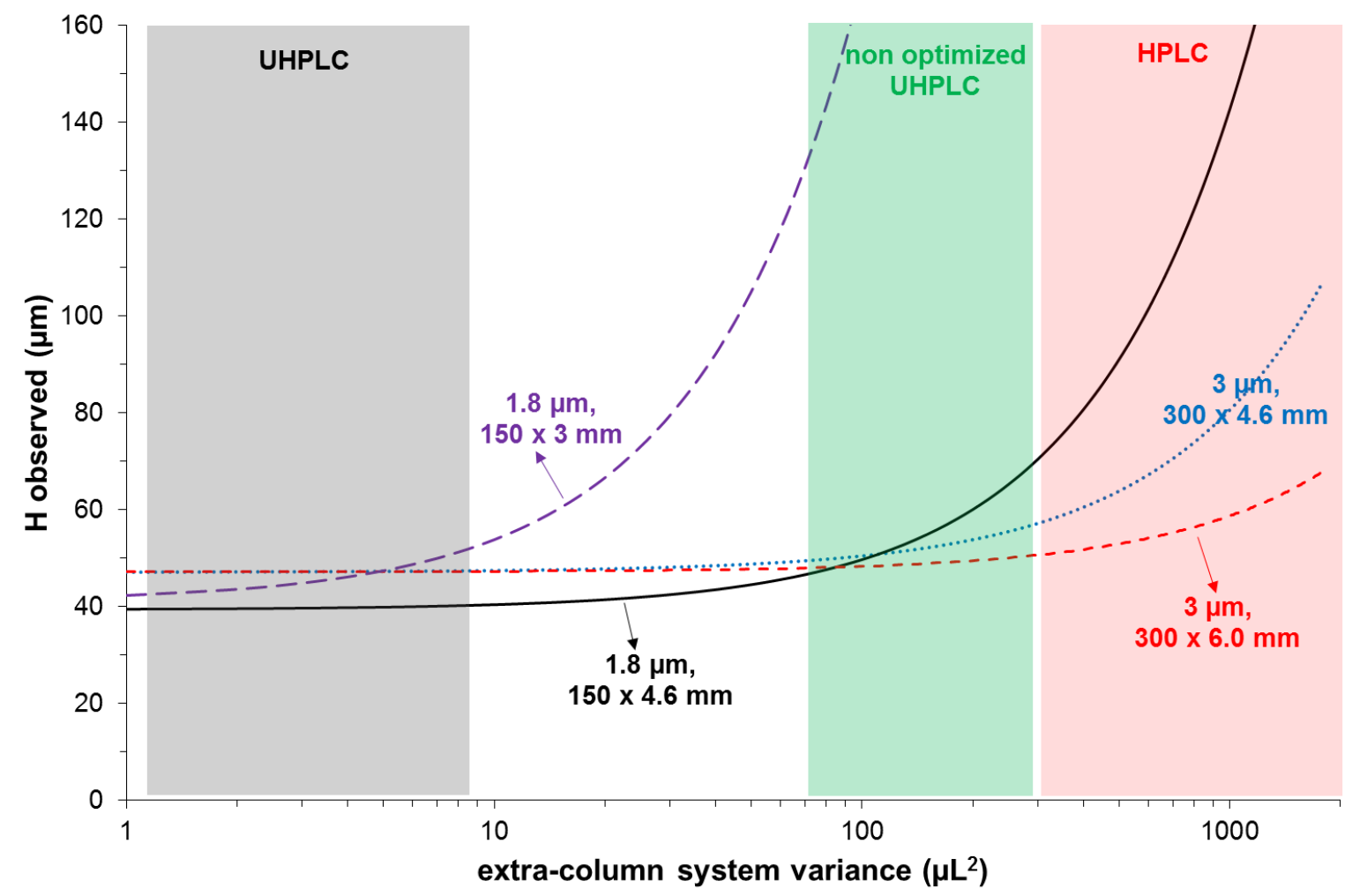

Figure 9. 